\title{
Competition in two-sided markets
}

\author{
Mark Armstrong*
}

Many markets involve two groups of agents who interact via "platforms," where one group's benefit from joining a platform depends on the size of the other group that joins the platform. I present three models of such markets: a monopoly platform; a model of competing platforms where agents join a single platform; and a model of "competitive bottlenecks" where one group joins all platforms. The determinants of equilibrium prices are (i) the magnitude of the crossgroup externalities, (ii) whether fees are levied on a lump-sum or per-transaction basis, and (iii) whether agents join one platform or several platforms.

\section{Introduction}

There are many examples of markets in which two or more groups of agents interact via intermediaries or "platforms." Surplus is created - or destroyed in the case of negative externalities when the groups interact. Of course, there are countless examples where firms compete to deal with two or more groups. Any firm is likely to do better if its products appeal to both men and women, for instance. However, in a set of interesting cases, cross-group externalities are present, and the benefit enjoyed by a member of one group depends upon how well the platform does in attracting custom from the other group. For instance, a heterosexual dating agency or nightclub can do well only if it succeeds in attracting business from both men and women. This article is about such markets. A brief list of other such markets includes: credit cards (for a given set of charges, a consumer is more likely to use a credit card that is accepted widely by retailers, while a retailer is more likely to accept a card that is carried by more consumers); television channels (where viewers typically prefer to watch a channel with fewer commercials, while an advertiser is prepared to pay more to place a commercial on a channel with more viewers); and shopping malls (where a consumer is more likely to visit a mall with a greater range of retailers, while a retailer is willing to pay more to locate in a mall with a greater number of consumers passing through). See Rochet and Tirole (2003) for further examples of two-sided markets.

As I shall argue in more detail, there are three main factors that determine the structure of prices offered to the two groups.

Relative size of cross-group externalities. If a member of group 1 exerts a large positive externality on each member of group 2 , then group 1 will be targeted aggressively by platforms. In broad terms, and especially in competitive markets, it is group 1's benefit to the other group

* University College London; mark.armstrong@ucl.ac.uk.

The first version of this article was presented at the Econometric Society European Meeting held in Venice, August 2002. I am grateful to the Editor and two referees, to the audiences at many seminar presentations, to Simon Anderson, Carli Coetzee, Jacques Crémer, Jean-Charles Rochet, Jean Tirole, Xavier Vives, and especially to Julian Wright for discussions and corrections. The support of the Economic and Social Reaserch Council (UK) is gratefully acknowledged. 
that determines group 1's price, not how much group 1 benefits from the presence of group 2 (see Proposition 2 below). In a nightclub, if men gain more from interacting with women than vice versa, then we expect there to be a tendency for nightclubs to offer lower entry fees to women than to men.

Unless they act to tip the industry to monopoly, positive cross-group externalities act to intensify competition and reduce platform profit - see expression (13) below. To be able to compete effectively on one side of the market, a platform needs to perform well on the other side (and vice versa). This creates a downward pressure on the prices offered to both sides compared to the case where no externalities exist. This implies that platforms have an incentive to find ways to mitigate network effects. One method of doing this is discussed next.

Fixed fees or per-transaction charges. Platforms might charge for their services on a lump-sum basis, so that an agent's payment does not explicitly depend on how well the platform performs on the other side of the market. Alternatively, if feasible, the payment might be an explicit function of the platform's performance on the other side. One example of this latter practice occurs when a television channel or a newspaper makes its advertising charge an increasing function of the audience or readership it obtains. Similarly, a credit card network levies (most of) its charges on a per-transaction basis, and the bulk of a real estate agent's fees are levied only in the event of a sale. The crucial difference between the two charging bases is that cross-group externalities are weaker with per-transaction charges, since a fraction of the benefit of interacting with an extra agent on the other side is eroded by the extra payment incurred. If an agent pays a platform only in the event of a successful interaction, the agent does not need to worry about how well the platform does in its dealings with the other side. That is, to attract one side of the market, it is not so important that the platform first gets the other side "on board." Because externalities are lessened with per-transaction charging, it is plausible that platform profit is higher when this form of charging is used. ${ }^{1}$ (See Propositions 3 and 5 for illustrations of this effect.) Finally, the distinction between the two forms of tariff only matters when there are competing platforms. When there is a monopoly platform (see Section 3), it makes no difference if tariffs are levied on a lump-sum or per-transaction basis.

$\square \quad$ Single-homing or multi-homing. When an agent chooses to use only one platform, it has become common to say the agent is "single-homing." When an agent uses several platforms, she is said to "multi-home." It makes a significant difference to outcomes whether groups single-home or multi-home. In broad terms, there are three cases to consider: (i) both groups single-home, (ii) one group single-homes while the other multi-homes, and (iii) both groups multi-home. If interacting with the other side is the primary reason for an agent to join a platform, then we might not expect case (iii) to be very common - if each member of group 2 joins all platforms, there is no need for any member of group 1 to join more than one platform - and so I do not analyze this configuration. (If all native French speakers also speak English, there is less incentive for a native English speaker to learn French.) Configuration (i) is discussed in Section 4. Although the analysis of that case provides useful insights about two-sided markets, it is hard to think of many actual markets that fit this configuration precisely.

By contrast, there are several important markets that resemble configuration (ii), and in Section 5 these are termed "competitive bottlenecks." Here, if it wishes to interact with an agent on the single-homing side, the multi-homing side has no choice but to deal with that agent's chosen platform. Thus, platforms have monopoly power over providing access to their singlehoming customers for the multi-homing side. This monopoly power naturally leads to high prices being charged to the multi-homing side, and there will be too few agents on this side being served

\footnotetext{
${ }^{1}$ An exception to this occurs when the market tips to monopoly. Here, an incumbent's profits typically increase with the importance of network effects, since entrants find it hard to gain a toehold even when the incumbent sets high prices. This explains one conclusion of Caillaud and Jullien (2003), which is that equilibrium profit rises when platforms cannot use transaction charges.
} 
from a social point of view (Proposition 4). ${ }^{2}$ By contrast, platforms do have to compete for the single-homing agents, and high profits generated from the multi-homing side are to a large extent passed on to the single-homing side in the form of low prices (or even zero prices).

\section{Related literature}

- I discuss some of the related literature later as it becomes most relevant in the analysis (especially in Section 5). However, it is useful to discuss two pioneering articles up front.

Caillaud and Jullien (2003) discuss the case of competing matchmakers, such as dating agencies, real estate agents, and internet "business-to-business" websites. (See also van Raalte and Webers (1998).) There is potentially a rich set of contracting possibilities. For instance, a platform might have a subscription charge in combination with a charge in the event of a successful match. In addition, Caillaud and Jullien allow platforms to set negative subscription charges and to make their profit from taxing transactions on the platform. Caillaud and Jullien first examine the case where all agents must single-home. (I provide a parallel analysis in Section 4.) In this case, there is essentially perfect competition, and agents have no intrinsic preference for one platform over another except insofar as one platform has more agents from the other side or charges lower prices. Therefore, the efficient outcome is for all agents to use the same platform. Caillaud and Jullien's Proposition 1 shows that the only equilibria in this case involve one platform attracting all agents (as is efficient) and that platform making no profit. The equilibrium structure of prices involves negative subscription fees and maximal transaction charges, since this is the most profitable way to prevent entry. Caillaud and Jullien go on to analyze the more complicated case where agents can multi-home. They analyze several possibilities, but the cases most relevant for my article are what they term "mixed equilibria" (see their Propositions 8 and 11). These correspond to my competitive bottleneck situations, and they involve one side multi-homing and the other side single-homing. They find that the single-homing side is treated favorably (indeed, its price is necessarily no higher than its cost), while the multi-homing side has all its surplus extracted. I discuss the relationship between the two approaches in more detail in Section 5.

Another closely related article is Rochet and Tirole (2003). The flavor of their analysis can be understood in the context of the credit card market (although the analysis applies more widely). On one side of the market are consumers, on the other side is the set of retailers, and facilitating the interaction between these two groups are two competing credit card networks. For much of Rochet and Tirole's analysis, the credit card platforms levy charges purely on a per-transaction basis, and there are no lump-sum fees for either side. Suppose that one credit card offers a lower transaction fee to retailers than its rival. A retailer choosing between accepting just the cheaper card or accepting both cards faces a tradeoff. If it accepts just the cheaper card, then its consumers have a stark choice between paying by this card or not using a card at all. Alternatively, if the retailer accepts both cards, then (i) more consumers will choose to pay by some card but (ii) fewer consumers will use the retailer's preferred lower-cost card. If a credit card reduces its charge to retailers relative to its rival, this will "steer" some retailers that previously accepted both cards to accept only the lower-cost card. In a symmetric equilibrium, all retailers accept both credit cards (or neither), while consumers always use their preferred credit card. The share of the charges that are borne by the two sides depends on how closely consumers view the two cards as substitutes. If few consumers switch cards in response to a price cut on their side, then consumers should pay a large share of the total transaction charge; if consumers view the cards as close substitutes, then retailers will bear most of the charges in equilibrium. Rochet and Tirole also consider the case where there are fixed fees as well as per-transaction fees, under the assumption that consumers use a single card. This is essentially the same model as my competitive bottleneck model, and I discuss this part of their article in more detail in Section 5.

${ }^{2}$ This tendency toward high prices for the multi-homing side is tempered when the single-homing side benefits from having many agents from the other side on their platform. Then high prices to the multi-homing side will drive away that side and disadvantage the platform when it tries to attract the single-homing side.

(c) RAND 2006 . 
There are a number of modelling differences between my article and Rochet and Tirole (2003) that concern the specification of agents' utility, the structure of platforms' fees, and the structure of platforms' costs. ${ }^{3}$ In both articles, agent $j$ has gross utility from using platform $i$ of the form

$$
u_{j}^{i}=\alpha_{j}^{i} n^{i}+\zeta_{j}^{i} .
$$

Here, $n^{i}$ is the number of agents from the other side who are present on platform $i, \alpha_{j}^{i}$ is the benefit that agent $j$ enjoys from interacting with each agent on the other side, and $\zeta_{j}^{i}$ is the fixed benefit the agent obtains from using that platform. Rochet and Tirole assume that $\zeta_{j}^{i}$ does not depend on $i$ or $j$ (and can be set equal to zero), but that $\alpha_{j}^{i}$ varies both with agent $j$ and platform $i$. In Sections 3 and 4 , by contrast, I assume that $\alpha_{j}^{i}$ does not depend on $i$ or $j$ but only on which side of the market the agent is on, while $\zeta_{j}^{i}$ depends on the agent and on the platform. (In Section 5, I suppose that the interaction term $\alpha$ for one side does vary across agents within a group.) The decision whether to make agents' heterogeneity to do with the interaction term $\alpha$ or the fixed benefit $\zeta$ has major implications for the structure of prices to the two sides in equilibrium. For instance, with a monopoly platform, the formulas for profit-maximizing prices look very different in the two articles. Moreover, when $\alpha_{j}^{i}$ depends on the platform $i$, an agent cares about which platform the transaction takes place on (if there is a choice): this effect plays a major role in Rochet and Tirole's analysis but is absent here. ${ }^{4}$

Turning to the structure of the platforms' fees, for the most part Rochet and Tirole assume that agents pay a per-transaction fee for each agent on the platform from the other side. If this fee is denoted $\gamma^{i}$, then agent $j$ 's net utility on platform $i$ is $u_{j}^{i}=\left(\alpha_{j}^{i}-\gamma^{i}\right) n^{i}$ (when $\zeta$ is set equal to zero). This confirms the discussion in Section 1 that per-transaction charges act to reduce the size of network effects. In the monopoly platform case, an agent's incentive to join the platform does not depend on the platform's performance on the other side, and she will join if and only if $\alpha_{j}^{i} \geq \gamma^{i}$. The present article, especially in Section 4, assumes that platform charges are levied as a lump-sum fee, say $p^{i}$, in which case the agent's net utility is $u_{j}^{i}=\alpha n^{i}+\zeta_{j}^{i}-p^{i}$. The final modelling difference between the two articles is with the specification of costs: Rochet and Tirole assume mainly that a platform's costs are incurred on a per-transaction basis, so that if a platform has $n_{1}$ group- 1 agents and $n_{2}$ group- 2 agents, its total cost is $c n_{1} n_{2}$ for some per-transaction cost $c$. In the current paper, costs are often modelled as being incurred when agents join a platform, so that a platform's total cost is $f_{1} n_{1}+f_{2} n_{2}$ for some per-agent costs $f_{1}$ and $f_{2}$. Which assumptions concerning tariffs and costs best reflect reality depends on the context. Rochet and Tirole's model is well suited to the credit card context, for instance, whereas the assumptions here are intended to apply to markets such as nightclubs, shopping malls, and newspapers.

\section{Monopoly platform}

- This section presents the analysis for a monopoly platform. This framework does not apply to most of the examples of two-sided markets that come to mind, although there are a few applications. For instance, yellow pages directories are often a monopoly of the incumbent telephone company, shopping malls or nightclubs are sometimes far enough away from others that the monopoly paradigm might be appropriate, and sometimes there is only one newspaper or magazine in the relevant market.

Suppose there are two groups of agents, denoted 1 and 2. A member of one group cares about

${ }^{3}$ The assumptions in Caillaud and Jullien (2003) to do with utility and costs are closer to mine than to those of Rochet and Tirole. Caillaud and Jullien do not have any intrinsic product differentiation between the platforms. However, there is a benefit to join two platforms rather than one, since they assume that there is a better chance of a match between buyers and sellers when two platforms are involved.

${ }^{4}$ A recent article that encompasses these two approaches with a monopoly platform is Rochet and Tirole (2006), where simultaneous heterogeneity in both $\alpha$ and $\zeta$ is allowed. However, a full analysis of this case is technically challenging in the case of competing platforms. 
the number of the other group who use the platform. (For simplicity, I ignore the possibility that agents care also about the number from the same group who join the platform.) Suppose the utility of an agent is determined in the following way: if the platform attracts $n_{1}$ and $n_{2}$ members of the two groups, the utilities of a group- 1 agent and a group- 2 agent are respectively

$$
u_{1}=\alpha_{1} n_{2}-p_{1} ; \quad u_{2}=\alpha_{2} n_{1}-p_{2},
$$

where $p_{1}$ and $p_{2}$ are the platform's prices to the two groups. The parameter $\alpha_{1}$ measures the benefit a group- 1 agent enjoys from interacting with each group- 2 agent, and $\alpha_{2}$ measures the benefit a group-2 agent obtains from each group-1 agent. Expression (1) describes how utilities are determined as a function of the numbers of agents who participate. To close the demand model, I specify the numbers who participate as a function of the utilities: if the utilities offered to the two groups are $u_{1}$ and $u_{2}$, suppose the numbers of each group who join the platform are

$$
n_{1}=\phi_{1}\left(u_{1}\right) ; \quad n_{2}=\phi_{2}\left(u_{2}\right)
$$

for some increasing functions $\phi_{1}(\cdot)$ and $\phi_{2}(\cdot)$.

Turning to the cost side, suppose the platform incurs a per-agent cost $f_{1}$ for serving group 1 and per-agent cost $f_{2}$ for group 2 . Therefore, the firm's profit is $\pi=n_{1}\left(p_{1}-f_{1}\right)+n_{2}\left(p_{2}-f_{2}\right)$. If we consider the platform to be offering utilities $\left\{u_{1}, u_{2}\right\}$ rather than prices $\left\{p_{1}, p_{2}\right\}$, then the implicit price for group 1 is $p_{1}=\alpha_{1} n_{2}-u_{1}$ (and similarly for group 2). Therefore, expressed in terms of utilities, the platform's profit is

$$
\pi\left(u_{1}, u_{2}\right)=\phi_{1}\left(u_{1}\right)\left[\alpha_{1} \phi_{2}\left(u_{2}\right)-u_{1}-f_{1}\right]+\phi_{2}\left(u_{2}\right)\left[\alpha_{2} \phi_{1}\left(u_{1}\right)-u_{2}-f_{2}\right] \text {. }
$$

Let the aggregate consumer surplus of group $i=1,2$ be $v_{i}\left(u_{i}\right)$, where $v_{i}(\cdot)$ satisfies the envelope condition $v_{i}^{\prime}\left(u_{i}\right) \equiv \phi_{i}\left(u_{i}\right)$. Then welfare, as measured by the unweighted sum of profit and consumer surplus, is

$$
w=\pi\left(u_{1}, u_{2}\right)+v_{1}\left(u_{1}\right)+v_{2}\left(u_{2}\right) .
$$

It is easily verified that the welfare-maximizing outcome has the utilities satisfying

$$
u_{1}=\left(\alpha_{1}+\alpha_{2}\right) n_{2}-f_{1} ; \quad u_{2}=\left(\alpha_{1}+\alpha_{2}\right) n_{1}-f_{2} .
$$

From expression (1), the socially optimal prices satisfy

$$
p_{1}=f_{1}-\alpha_{2} n_{2} ; \quad p_{2}=f_{2}-\alpha_{1} n_{1} .
$$

As one would expect, the optimal price for group 1, say, equals the cost of supplying service to a type-1 agent adjusted downward by the external benefit that an extra group- 1 agent brings to the group- 2 agents on the platform. (There are $n_{2}$ group- 2 agents on the platform, and each one benefits by $\alpha_{2}$ when an extra group-1 agent joins.) In particular, prices should be below cost if $\alpha_{1}, \alpha_{2}>0$.

From expression (2), the profit-maximizing prices satisfy

$$
p_{1}=f_{1}-\alpha_{2} n_{2}+\frac{\phi_{1}\left(u_{1}\right)}{\phi_{1}^{\prime}\left(u_{1}\right)} ; \quad p_{2}=f_{2}-\alpha_{1} n_{1}+\frac{\phi_{2}\left(u_{2}\right)}{\phi_{2}^{\prime}\left(u_{2}\right)} \text {. }
$$

Thus, the profit-maximizing price for group 1, say, is equal to the cost of providing service $\left(f_{1}\right)$, adjusted downward by the external benefit to group $2\left(\alpha_{2} n_{2}\right)$, and adjusted upward by a factor related to the elasticity of the group's participation. These profit-maximizing prices can be obtained in the familiar form of Lerner indices and elasticities, as recorded in the following result. 
Proposition 1. Write

$$
\eta_{1}\left(p_{1} \mid n_{2}\right)=\frac{p_{1} \phi_{1}^{\prime}\left(\alpha_{1} n_{2}-p_{1}\right)}{\phi_{1}\left(\alpha_{1} n_{2}-p_{1}\right)} ; \quad \eta_{2}\left(p_{2} \mid n_{1}\right)=\frac{p_{2} \phi_{2}^{\prime}\left(\alpha_{2} n_{1}-p_{2}\right)}{\phi_{2}\left(\alpha_{2} n_{1}-p_{2}\right)}
$$

for a group's price elasticity of demand for a given level of participation by the other group. Then the profit-maximizing pair of prices satisfy

$$
\frac{p_{1}-\left(f_{1}-\alpha_{2} n_{2}\right)}{p_{1}}=\frac{1}{\eta_{1}\left(p_{1} \mid n_{2}\right)} ; \quad \frac{p_{2}-\left(f_{2}-\alpha_{1} n_{1}\right)}{p_{2}}=\frac{1}{\eta_{2}\left(p_{2} \mid n_{1}\right)} .
$$

It is possible that the profit-maximizing outcome involves group 1, say, being offered a subsidized service, i.e., $p_{1}<f_{1}$. From (4), this occurs if the group's elasticity of demand is high and/or the external benefit enjoyed by group 2 is large. Indeed, the subsidy might be so large that the price is negative (or zero, if negative prices are not feasible). This analysis applies, in a stylized way, to a market with a monopoly yellow pages directory. Such directories typically are distributed for free, and profits are made solely from charges to advertisers. The analysis might also apply to software markets in which one type of software is required to create files in a certain format and another type is required to read such files. Often, the reading software is supplied for free, while the writing software needs to be paid for. (For the analysis to apply accurately, though, there need to be two disjoint groups of agents: those who wish to read files and those who wish to create files. It does not readily apply when most people wish to perform both tasks.)

\section{Two-sided single-homing}

- This model involves competing platforms but assumes for exogenous reasons that each agent chooses to join a single platform.

Basic model. The model extends the monopoly platform model in a natural way. There are two groups of agents, 1 and 2, and there are two platforms, $A$ and $B$, which enable the two groups to interact. Groups 1 and 2 obtain the respective utilities $\left\{u_{1}^{i}, u_{2}^{i}\right\}$ if they join platform $i$. These utilities $\left\{u_{1}^{i}, u_{2}^{i}\right\}$ are determined in a similar manner to the monopoly model expressed in (1): if platform $i$ attracts $n_{1}^{i}$ and $n_{2}^{i}$ members of the two groups, the utilities on this platform are

$$
u_{1}^{i}=\alpha_{1} n_{2}^{i}-p_{1}^{i} ; \quad u_{2}^{i}=\alpha_{2} n_{1}^{i}-p_{2}^{i},
$$

where $\left\{p_{1}^{i}, p_{2}^{i}\right\}$ are the respective prices charged by the platform to the two groups.

When group 1 is offered a choice of utilities $u_{1}^{A}$ and $u_{1}^{B}$ from the two platforms and group 2 is offered the choice $u_{2}^{A}$ and $u_{2}^{B}$, suppose the number of each group who join platform $i$ is given by the Hotelling specification

$$
n_{1}^{i}=\frac{1}{2}+\frac{u_{1}^{i}-u_{1}^{j}}{2 t_{1}} ; \quad n_{2}^{i}=\frac{1}{2}+\frac{u_{2}^{i}-u_{2}^{j}}{2 t_{2}} .
$$

Here, agents in a group are assumed to be uniformly located along a unit interval with the two platforms located at the two endpoints, and $t_{1}, t_{2}>0$ are the product differentiation (or transport cost) parameters for the two groups that describe the competitiveness of the two sides of the market.

Putting (6) together with (5), and using the fact that $n_{1}^{j}=1-n_{1}^{i}$, gives the following implicit expressions for market shares:

$$
n_{1}^{i}=\frac{1}{2}+\frac{\alpha_{1}\left(2 n_{2}^{i}-1\right)-\left(p_{1}^{i}-p_{1}^{j}\right)}{2 t_{1}} ; \quad n_{2}^{i}=\frac{1}{2}+\frac{\alpha_{2}\left(2 n_{1}^{i}-1\right)-\left(p_{2}^{i}-p_{2}^{j}\right)}{2 t_{2}} .
$$

Keeping its group-2 price fixed, expression (7) shows that an extra group-1 agent on a platform attracts a further $\alpha_{2} / t_{2}$ group- 2 agents to that platform. 
To focus on market-sharing equilibria, suppose the network externality parameters $\left\{\alpha_{1}, \alpha_{2}\right\}$ are small compared to the differentiation parameters $\left\{t_{1}, t_{2}\right\}$. (If network effects were large compared to brand preferences, then there could be equilibria only where one platform corners both sides of the market.) The necessary and sufficient condition for a market-sharing equilibrium to exist is

$$
4 t_{1} t_{2}>\left(\alpha_{1}+\alpha_{2}\right)^{2}
$$

and this inequality is assumed to hold throughout the following analysis.

Suppose platforms $A$ and $B$ offer the respective price pairs $\left(p_{1}^{A}, p_{2}^{A}\right)$ and $\left(p_{1}^{B}, p_{2}^{B}\right)$. Given these prices, solving the simultaneous equations (7) implies that market shares are

$$
n_{1}^{i}=\frac{1}{2}+\frac{1}{2} \frac{\alpha_{1}\left(p_{2}^{j}-p_{2}^{i}\right)+t_{2}\left(p_{1}^{j}-p_{1}^{i}\right)}{t_{1} t_{2}-\alpha_{1} \alpha_{2}} ; \quad n_{2}^{i}=\frac{1}{2}+\frac{1}{2} \frac{\alpha_{2}\left(p_{1}^{j}-p_{1}^{i}\right)+t_{1}\left(p_{2}^{j}-p_{2}^{i}\right)}{t_{1} t_{2}-\alpha_{1} \alpha_{2}} .
$$

(Assumption (8) implies that the denominators $t_{1} t_{2}-\alpha_{1} \alpha_{2}$ are positive.) As one would expect, if $\alpha_{1}, \alpha_{2}>0$, demand by the two groups is complementary, in the sense that a platform's market share for one group is decreasing in its price for the other group.

As with the monopoly model, suppose each platform has a per-agent cost $f_{1}$ for serving group 1 and $f_{2}$ for serving group 2 . Therefore, platform $i$ 's profit is

$$
\left(p_{1}^{i}-f_{1}\right)\left[\frac{1}{2}+\frac{1}{2} \frac{\alpha_{1}\left(p_{2}^{j}-p_{2}^{i}\right)+t_{2}\left(p_{1}^{j}-p_{1}^{i}\right)}{t_{1} t_{2}-\alpha_{1} \alpha_{2}}\right]+\left(p_{2}^{i}-f_{2}\right)\left[\frac{1}{2}+\frac{1}{2} \frac{\alpha_{2}\left(p_{1}^{j}-p_{1}^{i}\right)+t_{1}\left(p_{2}^{j}-p_{2}^{i}\right)}{t_{1} t_{2}-\alpha_{1} \alpha_{2}}\right] .
$$

This expression is quadratic in platform $i$ 's prices, and it is concave in these prices if and only if (8) holds. Therefore, platform $i$ 's best response to $j$ 's prices is characterized by the first-order conditions. Given (8), one can check that there are no asymmetric equilibria. For the case of a symmetric equilibrium where each platform offers the same price pair $\left(p_{1}, p_{2}\right)$, the first-order conditions for equilibrium prices are

$$
p_{1}=f_{1}+t_{1}-\frac{\alpha_{2}}{t_{2}}\left(\alpha_{1}+p_{2}-f_{2}\right) ; \quad p_{2}=f_{2}+t_{2}-\frac{\alpha_{1}}{t_{1}}\left(\alpha_{2}+p_{1}-f_{1}\right) .
$$

Expressions (10) can be interpreted in the following manner. First, note that in a Hotelling model without cross-group externalities, the equilibrium price for group 1 would be $p_{1}=f_{1}+t_{1}$. In this two-sided setting, the price is adjusted downward by the factor $\left(\alpha_{2} / t_{2}\right)\left(\alpha_{1}+p_{2}-f_{2}\right)$. This adjustment factor can be decomposed into two parts. The term $\left(\alpha_{1}+p_{2}-f_{2}\right)$ represents the external benefit to a platform when an additional group-2 agent is attracted. To see this, note first that the platform makes profit $\left(p_{2}-f_{2}\right)$ from an extra group- 2 agent. Second, $\alpha_{1}$ measures the extra revenue the platform can extract from its group-1 agents (without losing market share) when it has an extra group-2 agent. (An extra group- 2 agent means the utility of a group- 1 agent on the platform increases by $\alpha_{1}$, while the utility of the agent on the rival platform falls by $\alpha_{1}$. Therefore, the relative utility for group- 1 agents on the platform increases by $2 \alpha_{1}$. Since in equilibrium, a platform has half the group-1 agents, the extra revenue it can extract from its group- 1 agents is $\alpha_{1}$.) Thus $\left(\alpha_{1}+p_{2}-f_{2}\right)$ indeed represents the external benefit to a platform of attracting a marginal group-2 agent. Finally, as shown in (7), a platform attracts $\alpha_{2} / t_{2}$ extra group-2 agents when it has an extra group- 1 agent. In sum, the adjustment factor $\frac{\alpha_{2}}{t_{2}}\left(\alpha_{1}+p_{2}-f_{2}\right)$ measures the external benefit to the platform from attracting an extra group-1 agent; in other words, it measures the opportunity cost of raising the group- 1 price by enough to cause one group- 1 agent to leave. This discussion is summarized by an annotated version of formula (10):

$$
p_{1}=\underbrace{f_{1}}_{\text {cost }}+\underbrace{t_{1}}_{\text {market power }}-\underbrace{\left(\alpha_{2} / t_{2}\right)}_{\begin{array}{c}
\text { extra group-2 } \\
\text { agents }
\end{array}} \times \underbrace{\left(\alpha_{\text {group }}\right.}_{\begin{array}{c}
\left(\alpha_{1}+p_{2}-f_{2}\right) \\
\text { profit from an extra } \\
\text { group-2 agent }
\end{array}}
$$


Finally, solving the simultaneous equations in (10) implies that $p_{1}=f_{1}+t_{1}-\alpha_{2}$ and $p_{2}=f_{2}+t_{2}-\alpha_{1}$. This discussion is summarized in the next proposition.

Proposition 2. Suppose (8) holds. Then the model with two-sided single-homing has a unique equilibrium that is symmetric. Equilibrium prices for group 1 and group 2 are given respectively by

$$
p_{1}=f_{1}+t_{1}-\alpha_{2} ; \quad p_{2}=f_{2}+t_{2}-\alpha_{1}
$$

Thus, a platform will target one group more aggressively than the other if that group is (i) on the more competitive side of the market and/or (ii) causes larger benefits to the other group than vice versa. ${ }^{5}$

While the expressions (12) are certainly "simple," they are not intuitive, which is why the discussion focused on (10). The fact that, say, group 1's price does not depend on its own externality parameter $\alpha_{1}$ is surely an artifact of the Hotelling specification for consumer demand. The assumption that the total size of each group is fixed, so when platforms set low prices they steal business only from the rival rather than expand the overall market, greatly simplifies the analysis. While the solution as verbally described in equation (11) seems likely to hold more widely, the neat formulas in (12) will not. One disadvantage of using a framework with fixed group sizes, however, is that there is no scope for meaningful welfare analysis because prices are simply transfers between agents: any (symmetric) pair of prices chosen by platforms will yield the same total surplus.

It is useful to compare the competitive formulas (12) with the monopoly formulas (4). It turns out there is an extra effect with competition. From (7), a platform's own-price elasticity of demand given fixed and equal market share for the other group is $\eta_{1}=p_{1} / t_{1}$ and $\eta_{2}=p_{2} / t_{2}$ for group 1 and group 2 respectively. Thus, expression (12) may be rewritten as

$$
\frac{p_{1}-\left(f_{1}-2 \alpha_{2} n_{2}\right)}{p_{1}}=\frac{1}{\eta_{1}} ; \quad \frac{p_{2}-\left(f_{2}-2 \alpha_{1} n_{1}\right)}{p_{2}}=\frac{1}{\eta_{2}} .
$$

Comparing these expressions with the monopoly formulas (4) shows that a duopolist puts twice as much emphasis on the external benefit from one group when it sets its price to the other group. The reason for this difference is simple. When a monopoly platform sets a high price that induces an agent from one side to leave, that agent disappears from the market. When a duopoly platform sets a high price that induces an agent from, say, group 1 to leave, that agent does not disappear but instead joins the rival platform, and this makes it harder to attract group-2 agents.

From (12), in equilibrium each platform makes profit

$$
\pi=\frac{t_{1}+t_{2}-\alpha_{1}-\alpha_{2}}{2}
$$

Assumption (8) guarantees that this profit is positive. Positive cross-group externalities act to reduce profit compared to the case where $\alpha_{1}=\alpha_{2}=0$, since platforms have an additional incentive to compete hard for market share. Next, I discuss an extension where platforms can choose more complicated tariffs that reduce, or even reverse, these externalities.

Alternative tariffs. Uniform prices. In some contexts, it is natural to investigate the effect of price discrimination on prices and profit. For instance, are equilibrium profits higher or lower when nightclubs can charge different entry fees for women and men? Does the ability to target one side of the market without sacrificing revenues on the other side raise or lower profit? These issues can be addressed using the framework just discussed.

${ }^{5}$ A price in (12) can be negative if that side of the market involves a low cost, is competitive, or causes a large external benefit to the other side. It is often unrealistic to suppose negative prices are feasible, in which case the analysis needs to be adapted to incorporate the nonnegativity constraint - see Armstrong and Wright (forthcoming). 
Suppose that, say, $f_{1}=f_{2}=f$. (It makes little sense to discuss price discrimination if the costs are significantly different for the two groups.) Suppose platforms cannot set different prices to the two groups, and platform $i$ chooses the uniform price $p^{i}$. (Perhaps sex discrimination laws prevent differential pricing by nightclubs.) Platform $i$ 's profit is $\left(p^{i}-f\right)\left(n_{1}^{i}+n_{2}^{i}\right)$, and a platform cares only about the total number of agents it attracts. From (9), total demand for platform $i$ is

$$
n_{1}^{i}+n_{2}^{i}=1+\frac{1}{2} \frac{t_{1}+t_{2}+\alpha_{1}+\alpha_{2}}{t_{1} t_{2}-\alpha_{1} \alpha_{2}}\left(p^{j}-p^{i}\right)
$$

Therefore, the equilibrium uniform price is

$$
p=f+2 \frac{t_{1} t_{2}-\alpha_{1} \alpha_{2}}{t_{1}+t_{2}+\alpha_{1}+\alpha_{2}} .
$$

One can show that this uniform price (14) lies between the discriminatory prices in (12). Therefore, the consequence of a ban on price discrimination is that one group is made better off (the group that has the higher price with discriminatory pricing) while the other group is made worse off.

Equilibrium profits increase with discrimination if $p-f<(1 / 2)\left\{\left(p_{1}-f\right)+\left(p_{2}-f\right)\right\}$. Using expressions (12) and (14), it follows that this is the case if and only if

$$
\left(t_{1}-t_{2}\right)^{2}>\left(\alpha_{1}-\alpha_{2}\right)^{2}
$$

Condition (15) requires that the differences between the groups are more to do with differences in competitive conditions $(t)$ than with differences in external benefits $(\alpha)$. Thus, when differences are largely due to differences in $\alpha$, the ability of platforms to engage in price discrimination is damaging to their profits. Since total welfare is constant in this particular model, it follows that when condition (15) holds, consumers in aggregate are worse off when platforms engage in price discrimination. If, as seems plausible, price discrimination in, say, nightclubs, is more to do with asymmetries in cross-group benefits than with competitive conditions for the two groups, the use of price discrimination acts to make consumers in aggregate better off.

Two-part tariffs. The analysis so far has assumed that agents are charged a fixed fee to join a platform. There are several other kinds of tariffs that could be envisaged. For instance, Rochet and Tirole (2003) focus on the case where platforms levy charges on a per-transaction basis, i.e., the total charge to one group is proportional to the platform's realized market share of the other group. Alternatively, platforms could commit to supply agents with fixed utilities instead of charging a fixed price. Implicitly, there is then a commitment to reduce the charge that group-1 agents pay if it turns out that the market share for group 2 is smaller than expected, assuming that measurement problems do not preclude this. A more general formulation that encompasses these various possibilities is for platforms to offer a "two-part tariff," in which agents pay a fixed fee $p$ together with a marginal price, $\gamma$, for each agent on the other side who joins the platform. That is to say, platform $i$ 's tariffs to groups 1 and 2 are respectively

$$
T_{1}^{i}=p_{1}^{i}+\gamma_{1}^{i} n_{2}^{i} ; T_{2}^{i}=p_{2}^{i}+\gamma_{2}^{i} n_{1}^{i}
$$

Special cases of this family of tariffs include (i) $\gamma_{1}^{i}=\gamma_{2}^{i}=0$, where platforms compete in fixed fees as in the basic model presented above, and (ii) $\gamma_{1}^{i}=\alpha_{1}$ and $\gamma_{2}^{i}=\alpha_{2}$, where agents pay exactly the benefit they enjoy from interacting with an additional member of the other group. Thus, in case (ii) a platform commits to deliver a constant utility to customers, irrespective of its success on the other side of the market.

In general, each platform now has four degrees of freedom in its tariff choice. The analysis is more complicated than required in the basic model, and the details are left to the Appendix. This analysis is summarized in the following result. 
Proposition 3. Suppose assumption (8) holds. When platforms compete using two-part tariffs, a continuum of symmetric equilibria exist. ${ }^{6}$ Let $0 \leq \gamma_{1} \leq 2 \alpha_{1}$ and $0 \leq \gamma_{2} \leq 2 \alpha_{2}$ be marginal prices aimed at group 1 and group 2 respectively. An equilibrium exists where the two platforms offer the same pair of two-part tariffs to group 1 and group 2 of the form

$$
T_{1}=p_{1}+\gamma_{1} n_{2} ; \quad T_{2}=p_{2}+\gamma_{2} n_{1}
$$

where the fixed fees are given by

$$
p_{1}=f_{1}+t_{1}-\alpha_{2}+\frac{1}{2}\left(\gamma_{2}-\gamma_{1}\right) ; \quad p_{2}=f_{2}+t_{2}-\alpha_{1}+\frac{1}{2}\left(\gamma_{1}-\gamma_{2}\right) .
$$

The expressions (17) generalize (12) above. The profit of each platform in such an equilibrium is modified from (13) to be

$$
\pi=\frac{t_{1}+t_{2}-\alpha_{1}-\alpha_{2}}{2}+\frac{\gamma_{1}+\gamma_{2}}{4}
$$

This profit is increasing in the marginal prices $\gamma_{1}$ and $\gamma_{2}$. The reason that high marginal prices yield high profit is that they reduce, or even overturn, the cross-group network effects that make the market so competitive.

Thus, when platforms can use more ornate tariffs that depend on the platform's success on the other side of the market, a continuum of symmetric equilibria exist that are ranked by the profit they generate. In technical terms, the source of the multiple equilibria is related to the multiple equilibria that exist in a (deterministic) supply function framework - see Section 3 of Klemperer and Meyer (1989). The common issue in the two settings is that a firm, for a given choice of tariff by its rival, has a continuum of best responses.

The question arises of which of the equilibria in Proposition 3 is selected. One suggestion might be that platforms coordinate on an equilibrium that generates high profits, i.e., on a pair of tariffs with large $\gamma_{i} .{ }^{7}$ An alternative viewpoint is that the pure subscription tariffs analyzed in the basic model presented above are robust: if its rival offers a pure subscription tariff $\left(\gamma_{1}=\gamma_{2}=0\right)$, a platform has no incentive to offer a more ornate tariff that depends on its performance on the other side. However, more generally, this analysis suggests that, while it is straightforward to analyze the case of pure subscription tariffs (as in the basic model presented above) or the case of pure transaction tariffs (as emphasized in Rochet and Tirole (2003)), blending the two families of tariffs presents major problems for the predictive power of the model as formulated.

\section{Competitive bottlenecks}

- This section presents the third and final model, which is termed a model of "competitive bottlenecks." The model of Section 4 is modified by supposing that while group 1 continues to deal with a single platform (to single-home), group 2 wishes to deal with each platform (to multihome). Implicit in this model is the idea that group 2 puts more weight on the network benefits of being in contact with the widest population of group- 1 consumers than it does on the costs of dealing with more than one platform. The crucial difference between this model and that discussed in Section 4 is that here group 2 does not make an "either-or" decision to join a platform. Rather, keeping the market shares for group 1 constant, a group- 2 agent makes a decision to join one platform independently from its decision to join the other. ${ }^{8}$ In this sense, there is no competition between platforms to attract group- 2 customers.

\footnotetext{
${ }^{6}$ There are also asymmetric equilibria.

${ }^{7}$ As formulated here, there is no barrier to the platforms setting high prices $\gamma$ and generating high profits (and low utilities for agents). A more realistic model would have an outside option for agents, which would put a ceiling on prices.

${ }^{8}$ This is true if group-2 agents are atomistic. If not, then when a "large" group-2 agent that has already joined platform $A$ decides to join platform $B$, this will draw some group-1 agents away from platform $A$ and cause a negative externality on the surplus from the agent's platform $A$ interaction. Here, though, this possibility is ignored. 
There are several examples of markets where this framework seems a stylized representation. Consider the case of competing mobile telecommunications networks. (See Section 3.1 of Armstrong (2002) and Wright (2002) for formal models of this industry.) Subscribers wish to join at most one mobile network (i.e., they single-home). People on fixed telephony networks wish to call mobile subscribers. For a specified charge, someone can call any given mobile network, and in this sense, the people who call mobile networks multi-home. A mobile subscriber will choose the network with the tariff that leaves her with the most surplus. A mobile network's tariff has two ingredients: charges for subscription and outbound calls that affect the subscriber's utility directly, and charges the network makes to others for delivering calls to the subscriber (so-called call termination charges). Unless the subscriber cares directly about the welfare of people who might call her, the latter charges affect the subscriber's utility only insofar as they affect the number of calls she receives. (High termination charges will typically act to reduce the number of calls made to mobile networks, and this is detrimental to a subscriber's utility if she benefits from receiving calls.)

The tariffs that mobile networks set in equilibrium have low charges for subscription and outbound calls and high charges for call termination. In particular, the models predict that high profits made from call termination are passed on to subscribers in the form of subsidized handsets or similar inducements. More precisely, the equilibrium call-termination charge is chosen to maximize the welfare of mobile subscribers and mobile networks combined, and the interests of those who call mobile networks are ignored. This feature - that the single-homing side is treated well and the multi-homing side's interests are ignored in equilibrium-is a characteristic of the models presented below. A competitive bottleneck is present: even if the market for subscribers is highly competitive so that mobile networks have low equilibrium profits overall, there is no competition for providing communication services to these subscribers.

Other examples of this competitive bottleneck framework include: most people might read a single newspaper (perhaps due to time constraints), but advertisers might place ads in all relevant newspapers; consumers might choose to visit a single shopping mall (perhaps because of transport costs), but the same retailer might choose to open a branch in several malls; consumers might visit a single supermarket, but suppliers might wish to place their products on the shelves of several supermarkets; or a travel agent might use just one computerized airline reservation system, while airlines are forced to deal with all such platforms in order to gain access to each travel agent's customers. After analyzing a fairly general model of competitive bottlenecks, I shall present specific applications to newspapers and supermarkets.

$\square \quad$ A general framework. Suppose there are two, possibly asymmetric, platforms that facilitate interaction between two groups of agents. Suppose that group-2 agents are heterogeneous: if there are $n_{1}^{i}$ group-1 agents on platform $i$, the number of group- 2 agents prepared to pay a fixed fee $p_{2}^{i}$ to join this platform is denoted

$$
n_{2}^{i}=\phi^{i}\left(n_{1}^{i}, p_{2}^{i}\right)
$$

where the function $\phi^{i}$ is decreasing in $p_{2}^{i}$ and increasing in $n_{1}^{i}$. A group-2 agent's decision to join one platform does not depend on whether she chooses to join the rival platform. Let $R^{i}\left(n_{1}^{i}, n_{2}^{i}\right)$ denote platform $i$ 's revenue from group 2 when it has $n_{1}^{i}$ group-1 agents and sets its group-2 price such that $n_{2}^{i}$ group- 2 agents choose to join the platform. Formally, $R^{i}$ is defined by the relation

$$
R^{i}\left(n_{1}^{i}, \phi^{i}\left(n_{1}^{i}, p_{2}^{i}\right)\right) \equiv p_{2}^{i} \phi^{i}\left(n_{1}^{i}, p_{2}^{i}\right) .
$$

Similarly to expression (5), platform $i$ 's group-1 utility $u_{1}^{i}$ is given by

$$
u_{1}^{i}=U^{i}\left(n_{2}^{i}\right)-p_{1}^{i}
$$

if the platform charges $p_{1}^{i}$ to group 1 and $n_{2}^{i}$ group- 2 agents join the platform. Here $U^{i}$ is the (possibly nonlinear) function that measures the benefit that a group-1 agent enjoys with greater group-2 participation on the platform. (The function $U^{i}$ might be decreasing, for instance when 
newspaper readers find advertisements to be a nuisance.) If a group-1 agent's utility is $u_{1}^{i}$ with platform $i$, suppose the platform will attract

$$
n_{1}^{i}=\Phi^{i}\left(u_{1}^{i}, u_{1}^{j}\right)
$$

group-1 agents, where $\Phi^{i}$ is increasing in the first argument and decreasing in the second. If platform $i$ 's total cost of serving the two sides is denoted $C^{i}\left(n_{1}^{i}, n_{2}^{i}\right)$, its profit is

$$
\pi^{i}=n_{1}^{i} p_{1}^{i}+R^{i}\left(n_{1}^{i}, n_{2}^{i}\right)-C^{i}\left(n_{1}^{i}, n_{2}^{i}\right) .
$$

Next, the number of group-2 agents on each platform in equilibrium is derived as a function of the equilibrium market shares for group 1. Suppose that in equilibrium, platform $i$ offers utility $\hat{u}_{1}^{i}$ to its group- 1 agents and attracts a number $\hat{n}_{1}^{i}$ of such agents (given by the function $\Phi^{i}$ ). Then the platform must be maximizing its profits given this group-1 utility $\hat{u}_{1}^{i}$. Consider varying $p_{1}^{i}$ and $n_{2}^{i}$ so that utility $\hat{u}_{1}^{i}=U^{i}\left(n_{2}^{i}\right)-p_{1}^{i}$ is constant. Writing $p_{1}^{i}=U^{i}\left(n_{2}^{i}\right)-\hat{u}_{1}^{i}$ in (21) means that profit is

$$
\pi^{i}=\hat{n}_{1}^{i}\left[U^{i}\left(n_{2}^{i}\right)-\hat{u}_{1}^{i}\right]+R^{i}\left(\hat{n}_{1}^{i}, n_{2}^{i}\right)-C^{i}\left(\hat{n}_{1}^{i}, n_{2}^{i}\right) .
$$

Given $\hat{n}_{1}^{i}$, platform $i$ will choose to serve a number $\hat{n}_{2}^{i}$ of group-2 agents, where $\hat{n}_{2}^{i}$ maximizes

$$
\hat{n}_{1}^{i} U^{i}(\cdot)+R^{i}\left(\hat{n}_{1}^{i}, \cdot\right)-C^{i}\left(\hat{n}_{1}^{i}, \cdot\right)
$$

The equilibrium price to group 2 is $\hat{p}_{2}^{i}$, where this satisfies

$$
\hat{n}_{2}^{i}=\phi^{i}\left(\hat{n}_{1}^{i}, \hat{p}_{2}^{i}\right)
$$

For a given $\hat{n}_{1}^{i}$, notice that expression (22) measures the total surplus of platform $i$ and its group- 1 agents as the number of group- 2 agents is varied. Therefore, the number of group- 2 agents is chosen to maximize the joint interests of the platform and its group- 1 agents, and the interests of group 2 are ignored. In general, this implies that there is a market failure, and there is a suboptimal number of group- 2 agents on each platform for a given distribution of group-1 agents.

In more detail, suppose that the gross group-2 surplus on platform $i$ when that platform has $n_{1}^{i}$ group- 1 agents and $n_{2}^{i}$ group- 2 agents is denoted $V^{i}\left(n_{1}^{i}, n_{2}^{i}\right)$. When there are no externalities within the set of group 2-agents, this surplus function differentiates to give the inverse demand function, so that

$$
\frac{\partial}{\partial n_{2}^{i}} V^{i}\left(n_{1}^{i}, n_{2}^{i}\right) \equiv \frac{R^{i}\left(n_{1}^{i}, n_{2}^{i}\right)}{n_{2}^{i}} .
$$

(The right-hand side of this expression is just the price paid by group- 2 agents.) In some contexts, there are intragroup externalities present, and a group- 2 agent might be better off if there were fewer other group-2 agents on the same platform, in which case the formula (24) is not valid. The most obvious examples of this phenomenon are where shops or advertisers are competing among themselves to sell to consumers, and this situation is discussed below. When there are no intragroup externalities present in group 2 and (24) holds, there is an unambiguous market failure present, in that there are too few group- 2 agents on each platform for given numbers of group 1 . To see this, note that given its group-1 market share, total surplus on platform $i$ is maximized by choosing $n_{2}^{i}$ to maximize

$$
\hat{n}_{1}^{i} U^{i}(\cdot)+V^{i}\left(\hat{n}_{1}^{i}, \cdot\right)-C^{i}\left(\hat{n}_{1}^{i}, \cdot\right)
$$

Since $V^{i}\left(n_{1}^{i}, n_{2}^{i}\right)-R^{i}\left(n_{1}^{i}, n_{2}^{i}\right)$, group 2's net aggregate surplus, is increasing in $n_{2}^{i}$, the maximizer of (25) is greater than the maximizer of (22), and there are too few group-2 agents served in equilibrium.

This discussion is summarized in the next proposition. 
Proposition 4. In the competitive bottleneck model, in any equilibrium the number of group-2 agents on a platform is chosen to maximize the joint surplus of the platform and its group- 1 agents, and the interests of group 2 are ignored. Unless there are externalities within the set of group-2 agents, there are too few group- 2 agents on each platform given the distribution of group- 1 agents on each platform.

As with the mobile telephony case just discussed, in this model it does not make sense to speak of the competitiveness of "the market." There are two markets: the market for single-homing agents which is, to a greater or lesser extent, competitive, and a market for multi-homing agents where each platform holds a local monopoly. The excessive prices faced by the multi-homing side do not necessarily result in excess profits for platforms, since platforms might be forced by competitive pressure to transfer their monopoly revenues to the single-homing agents. Rather, the market failure is a suboptimal balance of prices to the two sides of the market.

Without putting more structure on this general model, it is hard to predict how their joint surplus is shared between platforms and group- 1 agents. The price charged to group 1 will depend in part on the strength of competition in the group-1 market for consumers (i.e., on the form of the functions $\Phi^{i}$ ). I investigate this further in the two applications that follow.

Informative advertising on media platforms. Consider a situation where advertisers wish to make contact with potential customers by placing ads on media platforms such as newspapers or yellow pages directories. Suppose there are two such platforms, $A$ and $B$, which are assumed to be symmetric. Ads are placed on the platforms by monopoly retailers ("group 2"). (See the discussion below for the case where advertisers or retailers compete with each other.) Assume readers ("group 1") use one or the other platform but not both. A reader will purchase some quantity of a given product if she sees an ad for the product and the product's price allows the consumer to enjoy nonnegative consumer surplus. The cost of producing and distributing an individual copy of a newspaper/directory is $c\left(n_{2}\right)$ when it contains $n_{2}$ ads. If there are no other costs, the cost function $C\left(n_{1}, n_{2}\right)$ used in the general framework presented above takes the multiplicative form

$$
C\left(n_{1}, n_{2}\right)=n_{1} c\left(n_{2}\right)
$$

Advertisers are characterized by the parameter $\alpha_{2}$ : a type- $\alpha_{2}$ advertiser has a product that generates profit $\alpha_{2}$ from each reader who sees its ad. Because each reader joins only one platform, an advertiser has no means with which to contact any particular reader except to place an ad on that reader's chosen platform. Thus, a type- $\alpha_{2}$ advertiser values an ad placed on a platform with readership $n_{1}$ at $\alpha_{2} n_{1} .{ }^{9}$ If the fixed charge for placing an ad on platform $i$ is $p_{2}^{i}$, then a type- $\alpha_{2}$ advertiser will place an ad on the platform if $\alpha_{2} n_{1}^{i} \geq p_{2}^{i}$. Suppose an advertiser's valuation $\alpha_{2}$ is unknown to a platform. Specifically, suppose for each advertiser the valuation $\alpha_{2}$ is independently and identically drawn from a distribution function $F\left(\alpha_{2}\right)$. From the viewpoint of the platforms, each advertiser is ex ante identical, and so a given platform will charge the same price $p_{2}$ to all advertisers. Therefore, the function $\phi$ in (18) is given by

$$
\phi\left(n_{1}^{i}, p_{2}^{i}\right)=1-F\left(p_{2}^{i} / n_{1}^{i}\right) .
$$

With an advertiser demand function of this form, the revenue function $R$ in (19) is proportional to the readership:

$$
R\left(n_{1}, n_{2}\right)=n_{1} r\left(n_{2}\right),
$$

where $r(\cdot)$ is a platform's advertising-revenue-per-reader function. (This function $r(\cdot)$ is defined by $r(1-F(\gamma)) \equiv(1-F(\gamma)) \gamma$.) In this case, expression (22) is proportional to $n_{1}^{i}$, and the

${ }^{9}$ Thus, an advertiser's payoff is proportional to the platform's readership. If a seller has limited supplies of the product (or, more generally, if its cost of production is convex), the seller only obtains benefit from the ad reaching a certain number of potential consumers, and then the linearity assumption would not be plausible. 
equilibrium advertising volume $\hat{n}_{2}$ maximizes

$$
U\left(n_{2}\right)+r\left(n_{2}\right)-c\left(n_{2}\right)
$$

regardless of the platform's performance on the group-1 side. Thus, a media platform's decision on its advertising volume can be made independently of the size of its readership.

Suppose, as in (6), there is a Hotelling functional form for the consumer market share function $\Phi^{i}$ in (20) given by

$$
n_{1}^{i}=\frac{1}{2}+\frac{u_{1}^{i}-u_{1}^{j}}{2 t}
$$

where $t$ is the parameter that measures the competitiveness of the market for readers. Therefore, the symmetric equilibrium (if it exists) involves the two platforms sharing readers equally: $\hat{n}_{1}^{i}=$ $\hat{n}_{1}^{j}=1 / 2$. Expression (23) then shows that the equilibrium charge to advertisers, $\hat{p}_{2}$, is given by

$$
\hat{n}_{2}=1-F\left(2 \hat{p}_{2}\right)
$$

where $\hat{n}_{2}$ is given by (27). Proposition 4 then implies that the equilibrium involves too little advertising. In this stark model, advertisers do not gain or lose when the market for readers becomes more competitive. For instance, if two newspapers merge in this model, advertisers will not be made worse off, since they will be forced to pay the same monopoly prices in either event.

This analysis was simplified by assuming that cost in (26) was proportional to readership. A richer model would include a per-advertiser platform cost in addition, since it is plausible that a platform incurs costs in dealing with each advertiser. In this case we would have, say, $C\left(n_{1}, n_{2}\right)=n_{1} c\left(n_{2}\right)+f_{2} n_{2}$. One could analyze the application to shopping malls using similar techniques. Here, a shopping mall's cost function would plausibly take the additive form

$$
C\left(n_{1}, n_{2}\right)=f_{1} n_{1}+f_{2} n_{2}
$$

Also, it is plausible to model retailers (or advertisers in the newspaper application) as having a fixed cost of joining a platform (the fixed cost associated with starting a shop or designing an ad) in addition to the platform's charge. However, the fundamental conclusion - that there will be too few retailers/advertisers in equilibrium - will continue to hold in these richer settings, as shown in Proposition 4.

Turn next to the outcome for readers. As in Section 4, it turns out that the equilibrium price depends on the way in which advertising charges are levied. There are two natural ways to charge advertisers: (i) advertising charges are explicitly levied on a per-reader basis, and (ii) advertisers are charged a lump-sum fee for placing an ad. ${ }^{10}$ The reason this makes a difference to the competitiveness of the market for readers is that it affects the profitability of a platform's deviation in the reader price. With case (i), if a platform attracts more readers, the number of ads does not change. ${ }^{11}$ With case (ii), by contrast, having more readers acts to attract more advertisers (keeping the lump-sum advertising charge constant), and this in turn acts to attract still more readers if readers like ads. (Note that the charging basis for advertising does not affect the equilibrium number of ads, given by $\hat{n}_{2}$, which maximizes (27) above.) I shall now discuss these two families of tariffs in more detail.

Per-reader advertising charges. Suppose that platform $i$ offers advertising space for a charge $\gamma^{i}$ per reader on the platform. Then a type- $\alpha_{2}$ advertiser will choose to join the platform if and only

${ }^{10}$ Unlike in Section 4, here I do not consider the more general class of two-part tariffs, where advertisers pay a fixed fee plus a charge per reader. From the earlier analysis, I expect there would be a problem of multiple equilibria if I did so.

${ }^{11}$ Conceptually, competing with per-reader charges is the same as competing in terms of quantities of advertising space, and the equilibrium price for ads is determined to clear the market, given the realized market shares for readers. 
if $\alpha_{2}>\gamma^{i}$, and the number of ads does not depend on the number of readers on the platform. In this case the analysis is simple. Both platforms will choose the number of ads $\hat{n}_{2}$ that maximizes (27), and this generates advertising revenue per reader equal to $r\left(\hat{n}_{2}\right)$. Since the two platforms offer the same number of ads, a reader cares only about the relative price when deciding which platform to use. Given the specification in (28), the profit of platform $i$ if it charges readers $p_{1}^{i}$ (while the rival platform charges readers $p_{1}^{j}$ ) is

$$
\pi^{i}=\left(\frac{1}{2}-\frac{p_{1}^{i}-p_{1}^{j}}{2 t}\right)\left(p_{1}^{i}+r\left(\hat{n}_{2}\right)-c\left(\hat{n}_{2}\right)\right) .
$$

Therefore, the symmetric equilibrium price for readers is given by

$$
p_{1}=c\left(\hat{n}_{2}\right)+t-r\left(\hat{n}_{2}\right)
$$

and a platform's revenue from advertising, $r\left(\hat{n}_{2}\right)$, is passed on to consumers in the form of a low price $p_{1}$. Platform profits are equal to the product differentiation parameter $t$.

When competition for readers is intense ( $t$ is small) or the advertising revenue $r\left(\hat{n}_{2}\right)$ is large, the price to readers is below cost. It might even be that the price in (30) is negative. If, as seems plausible, there is a nonnegativity constraint on prices, the equilibrium will involve group 1 being allowed onto the platform for free. This could be a rationale for why yellow pages directories and some newspapers are supplied to readers for free, why a shopping mall might not wish to charge consumers for entry even if it were feasible to do so, or why a broadcaster might wish not to charge viewers even when this is technologically feasible.

Lump-sum advertising charges. To analyze this more complex case, I need to calculate a platform's extra readership when it undercuts its rival's reader price. When a platform undercuts its rival on the reader side, it will clearly attract more readers; in consequence, the platform attracts more advertisers (given that its lump-sum charge for advertising is unchanged), which thereby attracts further readers if readers like ads. This feedback loop is absent when advertising charges are levied per reader. To be more precise, the advertising volume on platform $i$ as a function of readership $n_{1}^{i}$ is

$$
\tilde{n}_{2}\left(n_{1}^{i}\right)=1-F\left(\hat{p}_{2} / n_{1}^{i}\right),
$$

where the equilibrium lump-sum charge to advertisers $\hat{p}_{2}$ is given in expression (29). Using this notation, from (28) it follows that platform $i$ 's readership, $n_{1}^{i}$, must satisfy the following implicit equation:

$$
n_{1}^{i}=\frac{1}{2}+\frac{U\left(\tilde{n}_{2}\left(n_{1}^{i}\right)\right)-p_{1}^{i}-\left[U\left(\tilde{n}_{2}\left(1-n_{1}^{i}\right)\right)-p_{1}^{j}\right]}{2 t} .
$$

If (31) has multiple solutions for $n_{1}^{i}$, then there are multiple demand configurations consistent with the reader prices, and some method of choosing among the possible configurations is needed. To sidestep this issue, suppose model parameters are such that expression (31) has a unique solution in $n_{1}^{i}$ for all relevant prices $p_{1}^{i}$ and $p_{1}^{j}$. In Section 4, assumption (8) ruled out this possibility in the single-homing framework. It seems hard to find the precise corresponding assumption needed for the competitive bottleneck model. However, it is clear what is needed for there to be a unique solution to (31): $t$ should be "large" relative to $U^{\prime}$ and $\tilde{n}_{2}^{\prime}$. (This implies that the right-hand side of (31) is relatively flat as a function of $n_{1}^{i}$.) If $U^{\prime} \leq 0$, so that readers either do not care about ads or actively dislike them, then the right-hand side of (31) is decreasing in $n_{1}^{i}$ and there will always be a unique solution to (31). Armstrong and Wright (forthcoming) explore the issue of multiple consistent demand configurations and the existence of equilibrium in a related model where the group-2 agents are homogeneous (i.e., when $\tilde{n}_{2}^{\prime}$ is large). 
Implicit differentiation of (31) implies that

$$
\left.\frac{\partial n_{1}^{i}}{\partial p_{1}^{i}}\right|_{p_{1}^{i}=p_{1}^{j}}=\frac{-1}{2 t-2 \tilde{n}_{2}^{\prime}(1 / 2) U^{\prime}\left(\hat{n}_{2}\right)} .
$$

In particular, when readers like ads $\left(U^{\prime}>0\right)$, a platform's reader demand is more elastic than was the case with per-reader advertising charges (when $\left.\partial n_{1}^{i} / \partial p_{1}^{i}=-1 /(2 t)\right)$. When readers dislike ads $\left(U^{\prime}<0\right)$, by contrast, their demand is less elastic. The platform's profit is

$$
\pi^{i}=n_{1}^{i}\left[p_{1}^{i}-c\left(\tilde{n}_{2}\left(n_{1}^{i}\right)\right)+r\left(\tilde{n}_{2}\left(n_{1}^{i}\right)\right)\right] .
$$

Using expression (32), it follows that the equilibrium consumer price $p_{1}$ is

$$
p_{1}=c\left(\hat{n}_{2}\right)+t-r\left(\hat{n}_{2}\right)-\frac{1}{2} \tilde{n}_{2}^{\prime}\left(\frac{1}{2}\right)\left[2 U^{\prime}\left(\hat{n}_{2}\right)+r^{\prime}\left(\hat{n}_{2}\right)-c^{\prime}\left(\hat{n}_{2}\right)\right] .
$$

The first-order condition for the fact that $\hat{n}_{2}$ maximizes expression (27) then implies

$$
p_{1}=c\left(\hat{n}_{2}\right)+t-r\left(\hat{n}_{2}\right)-\frac{1}{2} \tilde{n}_{2}^{\prime}\left(\frac{1}{2}\right) U^{\prime}\left(\hat{n}_{2}\right) .
$$

Discussion. Comparing the reader price in expression (33) with that for the per-reader charging case in (30), we can see that when advertising charges are levied on a lump-sum basis, the equilibrium price for readers is lower or higher than when they are levied on a per-reader basis according to whether $U^{\prime}$ is positive or negative. Platform profits are correspondingly lower or higher with lump-sum charging according to whether $U^{\prime}$ is positive or negative. These results are akin to those presented in Section 4, where the use of tariffs that depend positively on the platform's success on the other side of the market was seen to relax competition and boost profits. In the knife-edge case where readers do not care about ads at all $\left(U^{\prime}=0\right)$, there is no difference between the regimes of lump-sum and per-reader charges for advertising. The reason for this is that with lump-sum charging there is no extra incentive for a platform to undercut its rival in the market for readers. While it is true that when platform $A$ gains readership at the expense of platform $B, B$ will find that its advertising demand shrinks; this effect no longer gives $A$ any advantage in the market for readers. This discussion is summarized in the final proposition.

Proposition 5. In the model of informative advertising on media platforms, if advertisers do not compete between themselves for consumers, there will be too few ads in equilibrium from a social point of view. If readers like (dislike) ads, when platforms charge advertisers on a lump-sum basis the equilibrium reader price and platform profit is lower (higher) than when advertising charges are levied on a per-reader basis.

The model presented here extends Gabszewicz, Laussel, and Sonnac (2001). That article proposes a model of the newspaper industry in which readers single-home and advertisers multihome. Therefore, although it is not emphasized in the article, they find there is monopoly pricing to advertisers and hence underprovision of advertising. Monopoly revenues from supplying advertising space are passed on to readers in the form of a subsidized price. Sometimes these revenues are so large that the newspaper is supplied to readers for free. ${ }^{12}$ The main difference is that in their article, readers are assumed to be indifferent to ads $\left(U^{\prime}=0\right.$ in the current notation). This implies that the outcome does not depend on whether lump-sum or per-reader advertising charges are used. As is clear from the previous discussion, when platforms use lump-sum advertising charges (which is arguably the more plausible scenario), the analysis is rather complicated when readers do care about advertising intensity.

\footnotetext{
12 Gabszewicz, Laussel, and Sonnac (2001) have an initial stage in which newspapers choose their political stance before competing for readers and dealing with advertisers. When advertising revenues are so high that newspapers are offered for free, they show that newspapers will choose the same centrist stance, whereas if newspapers compete in prices for readers, they will choose to differentiate their politics.
} 
Another related article, in the context of the television industry, is Anderson and Coate (2005). For the most part, they assume that viewers single-home and advertisers multi-home. It is arguable that the single-homing assumption is less natural in the television context than in the newspaper context, especially since the introduction of the remote control, and this is why I focused my discussion on newspapers and yellow pages. In contrast to Gabszewicz, Laussel, and Sonnac (2001), Anderson and Coate (2005) assume that viewers care (negatively) about advertising intensity. They analyze both the case where viewers are not charged for viewing and, more relevant for the current article, the case where viewers pay to view a television channel. In the latter case, they find there is too little advertising in equilibrium, for exactly the same reasons as outlined above. They assume that advertising charges are levied on a per-viewer basis, which avoids many of the complexities discussed above.

A third article that deserves mention is Kaiser and Wright (2006), who use data from German magazines to analyze which of the three models in this article (monopoly platform, two-sided single-homing, or competitive bottlenecks) fits that industry best. ${ }^{13}$ Magazines are grouped into genres (e.g., home improvement or photography), and model parameters are estimated for each of these three models. Within a genre, they find that readers are overwhelmingly single-homing, with about $8 \%$ of readers buying more than one magazine within a genre. Surprisingly, they also find that advertisers tend to be single-homing and to place an ad in just one magazine at a time (about $17 \%$ of advertisers multi-home). Perhaps magazines cater to differentiated readers, and many advertisers believe their product is suited to only one readership. In any event, the authors estimate that the two-sided single-homing model analyzed in Section 4 best explains the data. (However, they find that the market for readers is more competitive than the market for advertisers.)

Supermarkets. A second application of the competitive bottleneck model is to supermarkets and similar kinds of retailers. A commonly held view about the supermarket sector is that, provided competition for consumers is vigorous, consumers are treated well by supermarkets but supermarkets deal too aggressively with their suppliers. The model when applied to this industry can generate these stylized features.

Suppose two supermarkets compete to attract consumers. Consumers ("group 1") care both about the prices they pay and the range of products on offer. They visit either one supermarket or the other (but not both) over the relevant time period. Suppose there is a continuum of monopoly products ("group 2"), each of which could be supplied to either or both supermarkets. For simplicity, suppose each consumer wishes to buy one unit of each product so long as the price of the product is less than their reservation value, $\alpha_{1}$. (Thus, consumers view the various products as being equally valuable and as neither substitutes nor complements in their utility function.) Suppose that supermarkets incur a cost $c$ for selling each unit of any product. ${ }^{14}$ Supermarkets are assumed to set retail prices to their consumers and to make take-it-or-leave-it offers to buy from their suppliers. In particular, supermarkets hold all the bargaining power when dealing with their suppliers.

As in the case of advertising on media platforms, suppose that the unit cost of supply for any product is unknown to a supermarket and that for each product the unit $\operatorname{cost} \alpha_{2}$ is independently and identically drawn from a distribution function $F\left(\alpha_{2}\right)$. From the supermarkets' viewpoint, each supplier is ex ante identical, and so a given supermarket will make the same offer to all suppliers to buy at the per-unit price $p_{2}$. (Note that, unlike other models discussed, this is a payment from the platform to the group- 2 agents. Note also that the context makes it natural to assume platforms make their payments to suppliers on a per-transaction rather than lump-sum basis.) The number of suppliers that agree to this level of compensation is $F\left(p_{2}\right)$. If a supermarket sets a retail price $p_{1}$ per unit to consumers, a consumer's utility from visiting the supermarket is the number of

\footnotetext{
${ }^{13}$ Also see Rysman (2004), who estimates the size of cross-group externalities in the market for yellow pages.

${ }^{14}$ With some extra complexity, one could extend this simple framework to allow for per-consumer costs (e.g., car parking and checkout facilities) and for per-product costs.

(c) RAND 2006 .
} 
products multiplied by the net surplus per product

$$
u_{1}=F\left(p_{2}\right)\left(\alpha_{1}-p_{1}\right)
$$

whereas the supermarket's profit per consumer is

$$
\pi=F\left(p_{2}\right)\left(p_{1}-c-p_{2}\right)
$$

Regardless of its market share of consumers, a supermarket will choose $p_{1}$ and $p_{2}$ to maximize its profit per consumer, $\pi$, subject to delivering a required utility $u_{1}$. Expressions (34) and (35) then imply that

$$
p_{2} \text { maximizes } F\left(p_{2}\right)\left(\alpha_{1}-c-p_{2}\right) \text {. }
$$

As with all the competitive bottleneck models, in equilibrium the joint surplus of the platforms and the single-homing group is maximized (supermarkets and consumers in this case, as given in expression (36)), and the interests of the multi-homing side (the suppliers) are ignored. The low level of compensation in (36) will exclude some relatively high-cost suppliers whose presence in the supermarkets is nevertheless efficient. (A supplier should supply if $\alpha_{2}<\alpha_{1}-c$, whereas the equilibrium price $p_{2}$ in expression (36) is strictly lower than $\alpha_{1}-c$ and supply is inefficiently restricted.) In other words, payments to suppliers are too low from a social point of view and there are too few products on the shelves.

How well consumers are treated depends on competitive conditions on their side. If they choose their supermarket according to the Hotelling specification in (28), one can show their equilibrium utility $u_{1}$ is given by

$$
u_{1}=F\left(p_{2}\right)\left(\alpha_{1}-c-p_{2}\right)-t
$$

so that consumers keep the joint surplus $F\left(p_{2}\right)\left(\alpha_{1}-c-p_{2}\right)$ except for the market power element $t$ retained by the supermarkets. (An explicit expression for the equilibrium per-unit price to consumers is $p_{1}=c+p_{2}+t / F\left(p_{2}\right)$.)

As with the previous model of informative advertising, the treatment of suppliers is not affected by the strength of competition between supermarkets for consumers. In this model, if two supermarkets merge, consumers would be treated less favorably but suppliers would not be affected. Their compensation in (36) anyway is the payment that would be chosen if there were a single monopoly supermarket.

In this model, supermarkets act to reverse the bargaining asymmetry that consumers might otherwise have in their dealings with individual monopoly suppliers..$^{15}$ For instance, suppose without the institution of supermarkets the suppliers sell directly to consumers. (Again, though, there are two "shopping centers" in the same locations as the supermarkets, and suppliers sell in both of these areas. For consistency with the supermarket analysis, suppose also that each supplier incurs the selling cost $c$ per unit in addition to its supply cost $\alpha_{2}$.) In this case, those suppliers with cost $c+\alpha_{2}$ below the consumer reservation price $\alpha_{1}$ would choose to supply at the monopoly price $p_{1}=\alpha_{1}$. (Because there is a continuum of suppliers, each supplier sets its price without regard for the effect its high price has on the number of consumers who visit the local shopping area.) This move to direct supply clearly makes consumers worse off, although it does improve efficiency because the competitive bottleneck is overcome and the range of products supplied is efficient. ${ }^{16}$

${ }^{15}$ Dobson and Waterson (1997) analyze a model where supermarkets bargain with suppliers over supply prices, and where a merger between two supermarkets improves the bargaining position of supermarkets and so drives down the equilibrium supply prices. In extreme cases they show that a merger between supermarkets might lead to lower retail prices for consumers.

${ }^{16}$ The change from a situation where suppliers sell their products directly to consumers as opposed to selling to a supermarket corresponds to the distinction made in Smith and Hay (2005) between "streets" and "supermarkets." They 
The same logic suggests that suppliers are likely to be better off when they act independently than when they integrate to form a supermarket. Independent suppliers do not take account of the negative effect on other suppliers in the same shopping area when they set high prices. When suppliers merge to form a supermarket, they internalize the effect that each supplier's pricing decision has on the overall attractiveness of the shopping center for consumers, and this makes competition between shopping centers more intense. Lack of coordination between independent suppliers acts as a kind of commitment to price high in a shopping area, and this boosts profit. (See Beggs (1994) for further analysis of this point.)

Intraplatform competition. An interesting issue concerns the extent of competition between retailers within platforms. For instance, a television channel might charge more for a car ad if it promised not to show a rival manufacturer's ad in the same slot. A shopping mall might charge a higher rent to a retailer with the promise that it will not let a competing retailer into the same mall. Implementing competition within a platform will often mean that retailers' prices and profits are lower than they would be with monopoly retailers. ${ }^{17}$ Thus we may expect that if the platform allowed retailing competition, it would make less money from the retailing side of the market but more money from the consumer side (if it charged consumers for entry). A plausible hypothesis is: platforms will allow competition within the platform if consumers can be charged for entry, but if for exogenous reasons consumers have free entry, then platforms will restrict competition to drive up the revenues obtained from retailers.

This topic deserves a separate article to itself. Here I merely describe a stylized example to show the plausibility of the hypothesis. Suppose there are two platforms that can serve any number of consumers and retailers costlessly $\left(C\left(n_{1}, n_{2}\right) \equiv 0\right.$ in the general model presented above). If consumers receive utility $u_{1}^{i}$ from platform $i$, suppose the market share of platform $i$ is given by expression (28). Suppose there is a single, homogeneous product supplied by a group of identical retailers. If the retail price for this product is $P$, each consumer demands a quantity $q(P)$ of the product. Let $v(P)$ be the consumer surplus associated with this demand function. Each retailer has marginal cost $C$ for supplying a unit of the product. Suppose there is no fixed cost associated with a retailer locating in a given platform (other than the platform charge for entry).

A platform must decide whether to have retailing competition or not (i.e., whether to have more than one retailer on the platform). Suppose that a retailer chooses its price on a platform to reflect competitive conditions on that platform. (That is, retailers can price discriminate from one platform to the other.) If there is competition on the platform, the price of the product on the platform is equal to marginal $\operatorname{cost} C$. If there is no competition on the platform, the product's price will be above cost, and the price-cost markup will depend on the extent of competition between platforms.

First, suppose platforms can charge consumers for access to the platform. In this case, it is optimal for platform $i$ to choose to have competition on the platform. To see this, suppose that the rival platform offers consumers a utility $u_{1}^{j}$. (It does not matter whether this utility is achieved by means of competition within the rival platform or not.) If the product has price $P^{i}$ on platform $i$ and consumers pay $p_{1}^{i}$ to gain access to the platform, consumers obtain utility $u_{1}^{i}=v\left(P^{i}\right)-p_{1}^{i}$ from that platform. Therefore, given (28), the joint profit of platform $i$ and the retailer(s) on this platform is

$$
\left(\frac{1}{2}+\frac{v\left(P^{i}\right)-p_{1}^{i}-u_{1}^{j}}{2 t}\right)\left(q\left(P^{i}\right)\left(P^{i}-C\right)+p_{1}^{i}\right) .
$$

propose a slightly different model and find more generally that the comparison of the number of products supplied in the two situations is ambiguous.

${ }^{17}$ Stahl (1982) analyzes a model where a retailer's profit might increase if a retailer supplying an imperfect substitute locates in the same shopping center. The greater variety of products attracts more consumers to the shopping center, which might outweigh the more intense competition within the shopping center. (See Schutz and Stahl (1996) for a related search model.) By contrast, in the model presented here, competition drives profit to zero.

(c) RAND 2006 
Rewriting this in terms of $u_{1}^{i}=v\left(P^{i}\right)-p_{1}^{i}$, this joint profit is

$$
\left(\frac{1}{2}+\frac{u_{1}^{i}-u_{1}^{j}}{2 t}\right)\left(q\left(P^{i}\right)\left(P^{i}-C\right)+v\left(P^{i}\right)-u_{1}^{i}\right) .
$$

Clearly, for any $\left(u_{1}^{i}, u_{1}^{j}\right)$ this joint profit is maximized by choosing $P^{i}=C$, i.e., by implementing competition, and moreover this joint profit is then entirely appropriated by the platform. Therefore, when consumers can be charged for access to the platform, the competitive option is the most profitable way for a platform to generate any given level of consumer utility. This is a dominant strategy and does not depend on whether the rival platform chooses to have competition. The platform obtains all of its revenue from the consumer side. It is straightforward to show that the equilibrium charge for access by consumers to the platforms is $p_{1}=t$ (and the price for the product on the platforms is $P=C$ ).

Second, suppose that for some exogenous reason platforms cannot charge consumers for access and so must make their profit from the retailer side. (For instance, television channels historically could not charge viewers for access and so had to fund their service entirely from the advertising side.) The only way a platform can set a positive price to a retailer in this stark framework is if the retailer is a local monopoly, so platforms will restrict competition in order to obtain any revenue at all. The monopoly retailer on platform $i$ will make profit

$$
\left(\frac{1}{2}+\frac{v\left(P^{i}\right)-v\left(P^{j}\right)}{2 t}\right) q\left(P^{i}\right)\left(P^{i}-C\right)
$$

if it sets the price $P^{i}$ and the monopoly on the rival platform sets the price $P^{j}$. The platform can then extract this profit by means of its charge to the retailer. Suppose the monopoly retailers on the two platforms are separately owned. One can then show that the equilibrium product price $P$ is close to the monopoly price (i.e., the price that maximizes $q(P)(P-C)$ ) when $t$ is large and is close to $\operatorname{cost} C$ when $t$ is small. One can also show that consumers in this framework are always worse off when platforms can charge them for access compared to when they have free access, despite the fact that they pay a lower price for the product once they are on the platform. (See Corollary 1 in Armstrong and Vickers (2001).)

An article that relates to this discussion is Dukes and Gal-Or (2003). They have a model where competing producers place ads on competing media platforms. They assume that the platforms are broadcasters who do not charge viewers/listeners for access to the platform. Consistent with the above discussion, they find that a media platform (usually) sells advertising space exclusively to one firm from the producer oligopoly.

Discussion. Section 2 discussed two important precursors to this article. Let us now rejoin this discussion to point out the relationships between the three competitive bottleneck models in the articles. First, consider Proposition 11 in Caillaud and Jullien (2003). In the notation of Section 4 of the current article, those authors present a model in which there is no intrinsic product differentiation between the two platforms, where group- 1 agents have a benefit $\alpha_{1}$ from interacting with each group- 2 agent, and where group- 2 agents each have a benefit $\alpha_{2}$ from interacting with each group-1 agent. (Thus there is no variation in $\alpha_{2}$ as there was in this section.) Caillaud and Jullien show that there is a symmetric equilibrium of the following form (provided $\alpha_{2} / 2>f_{2}$ ). Group 1 single-homes and divides equally between the two platforms, while group- 2 agents join both platforms. The price to group 1 equals their cost, $p_{1}=f_{1}$, while the price to group 2 fully extracts their surplus, so $p_{2}=\alpha_{2} / 2$. This forms an equilibrium because a platform has no incentive to undercut its rival on either side of the market. If the platform sets a price $p_{2}<\alpha_{2} / 2$, this has no effect on group 2's choice and will not boost demand from that side. If the platform sets a price $p_{1}<f_{1}$, this will attract all group- 1 agents but will not affect demand by group 2 , so this deviation will reduce the platform's profit given that the price is below cost. ${ }^{18}$ Thus positive profits

${ }^{18}$ Here one important issue is not discussed. If the deviating platform simultaneously reduces $p_{1}$ and increases $p_{2}$, there are multiple consistent demand configurations, and for the stated prices to form an equilibrium, a particular choice 
can be sustained in equilibrium even when two identical platforms compete. A feature of Caillaud and Jullien's model is that demands are discontinuous in prices: a small price reduction to group 1 means that the platform attracts the entire set of group- 1 agents, and this feature implies that it can never be optimal to set a price $p_{1}>f_{1}$. (Due to the finite cross-elasticities in the present model, there is no reason to rule out above-cost pricing to the single-homing side.) However, a small price reduction to the multi-homing side has no effect on demand, and this provides the source of profits in this industry.

Second, consider Section 6 of Rochet and Tirole (2003). Up to that section, they consider either a monopolist charging two-part tariffs or platform competition in pure transaction prices. Using the notation for two-part tariffs in Section 4 of the current article, Section 6 of Rochet and Tirole supposes that platforms can be taken to compete in the "per-transaction" prices $P_{1}^{i}$ and $P_{2}^{i}$, defined by

$$
P_{1}^{i}=\gamma_{1}^{i}+\frac{p_{1}^{i}-f_{1}}{n_{2}^{i}} ; \quad P_{2}^{i}=\gamma_{2}^{i}+\frac{p_{2}^{i}-f_{2}}{n_{1}^{i}} .
$$

The interpretation of this game is that platforms commit to per-transaction prices and settle accounts with their customers once market shares and transactions have been recorded. It is important to note, though, that assuming platforms commit to per-transaction prices is not equivalent to assuming they offer two-part tariffs. Specifically, it is true that for a given pair of two-part tariffs offered by platform $j$, platform $i$ 's payoff only depends on its own tariffs via the summary prices $P_{1}^{i}$ and $P_{2}^{i}$ above. However, for the reasons outlined in Section 4, platform $i$ 's particular choice of two-part tariffs (among those tariffs with the same per-transaction prices $P_{1}^{i}$ and $P_{2}^{i}$ ) does matter for platform $j$, since it affects $j$ 's incentive to deviate. Namely, an aggressive move by platform $j$ has more impact on $j$ 's market share under competition in two-part tariffs, since its effect on platform $i$ 's customers is not dampened by a commitment to per-transaction prices. Equilibria therefore depend on the modelling choice of strategic variable. The assumption that platforms compete using two-part tariffs is perhaps more descriptive of existing two-sided markets.

There are at least three limitations to the present analysis of competitive bottlenecks. First, in the applications I made the simplifying assumption that the population of group- 1 agents was constant. Thus, the fact that this group tends to be treated favorably in equilibrium has no effect on the number of such agents who choose to participate. If instead there were a market expansion effect, this would make group 2 better off, because they have more group- 1 agents with whom to interact. In principle, it is conceivable that this effect could imply that the number of group- 2 agents served is not too small from a social point of view. However, this turns out not to be possible. (See Armstrong (2002) for this analysis in the telecommunications context.)

Second, I made the convenient assumption that no group-1 agents multi-homed. A richer model would allow for some agents to multi-home (for instance, some people read two newspapers, some people might go to one supermarket for some products and another supermarket for other products, and so on). Platforms then no longer have a monopoly over providing access by group 2 to these multi-homing group-1 agents. So far, little progress has been made in extending the analysis to these mixed situations, and this is a fruitful topic for future research. (See Section 7.1 of Anderson and Coate (2005) for a first step in this direction.)

Third and finally, I did not consider a platform's incentive to require an otherwise multihoming agent to deal with it exclusively. It is plausible in the context of the competitive bottleneck model that a platform might try to sign up group-2 agents exclusively, in order to give it an advantage in the market for group-1 agents. Of course, if platforms succeed in forcing group-2 agents to decide to deal with one platform or the other, then platforms will find themselves in the two-sided single-homing situation analyzed in Section 4. Because network effects are so strong in that situation, it is plausible that platforms find their equilibrium profits decrease when they

for the demand configuration needs to be made. See Armstrong and Wright (forthcoming) for further discussion of this issue. 
force group 2 to deal exclusively. (See Armstrong and Wright (forthcoming) for further analysis of exclusive contracts within this framework.)

\section{Appendix}

- In this Appendix I supply the proof of Proposition 3. Suppose that platform $i$ 's tariffs take the form in (16) above. If a group- 1 agent joins platform $i$, she obtains utility

$$
u_{1}^{i}=\left(\alpha_{1}-\gamma_{1}^{i}\right) n_{2}^{i}-p_{1}^{i}
$$

and so the number of group-1 and group-2 agents who join platform $i$ is

$$
\begin{aligned}
& n_{1}^{i}=\frac{1}{2}+\frac{\left(\alpha_{1}-\gamma_{1}^{i}\right) n_{2}^{i}-\left(\alpha_{1}-\gamma_{1}^{j}\right)\left(1-n_{2}^{i}\right)-\left(p_{1}^{i}-p_{1}^{j}\right)}{2 t_{1}} \\
& n_{2}^{i}=\frac{1}{2}+\frac{\left(\alpha_{2}-\gamma_{2}^{i}\right) n_{1}^{i}-\left(\alpha_{2}-\gamma_{2}^{j}\right)\left(1-n_{1}^{i}\right)-\left(p_{2}^{i}-p_{2}^{j}\right)}{2 t_{2}} .
\end{aligned}
$$

By solving this pair of equations in $n_{1}^{i}$ and $n_{2}^{i}$, one obtains the following explicit formulas for $n_{1}^{i}$ and $n_{2}^{i}$ in terms of the eight tariff parameters:

$$
\begin{aligned}
& n_{1}^{i}=\frac{1}{2}+\frac{1}{2} \frac{\left(2 \alpha_{1}-\gamma_{1}^{i}-\gamma_{1}^{j}\right)\left(2 p_{2}^{j}-2 p_{2}^{i}+\gamma_{2}^{j}-\gamma_{2}^{i}\right)+t_{2}\left(4 p_{1}^{j}-4 p_{1}^{i}+2 \gamma_{1}^{j}-2 \gamma_{1}^{i}\right)}{4 t_{1} t_{2}-\left(2 \alpha_{1}-\gamma_{1}^{j}-\gamma_{1}^{i}\right)\left(2 \alpha_{2}-\gamma_{2}^{j}-\gamma_{2}^{i}\right)} \\
& n_{2}^{i}=\frac{1}{2}+\frac{1}{2} \frac{\left(2 \alpha_{2}-\gamma_{2}^{i}-\gamma_{2}^{j}\right)\left(2 p_{1}^{j}-2 p_{1}^{i}+\gamma_{1}^{j}-\gamma_{1}^{i}\right)+t_{1}\left(4 p_{2}^{j}-4 p_{2}^{i}+2 \gamma_{2}^{j}-2 \gamma_{2}^{i}\right)}{4 t_{1} t_{2}-\left(2 \alpha_{1}-\gamma_{1}^{j}-\gamma_{1}^{i}\right)\left(2 \alpha_{2}-\gamma_{2}^{j}-\gamma_{2}^{i}\right)}
\end{aligned}
$$

Equilibrium prices are determined by the sensitivities of market shares to changes in the various prices. To determine symmetric equilibria, I calculate the derivative of market shares with respect to changes in prices, evaluated when the two platforms set the same quadruple of prices $\left(p_{1}, p_{2}, \gamma_{1}, \gamma_{2}\right)$ :

$$
\begin{aligned}
& \frac{\partial n_{1}^{i}}{\partial p_{1}^{i}}=-\frac{t_{2}}{2 \Delta} ; \quad \frac{\partial n_{1}^{i}}{\partial \gamma_{1}^{i}}=-\frac{t_{2}}{4 \Delta} \\
& \frac{\partial n_{2}^{i}}{\partial p_{2}^{i}}=-\frac{t_{1}}{2 \Delta} ; \quad \frac{\partial n_{2}^{i}}{\partial \gamma_{2}^{i}}=-\frac{t_{1}}{4 \Delta} \\
& \frac{\partial n_{1}^{i}}{\partial p_{2}^{i}}=-\frac{\alpha_{1}-\gamma_{1}}{2 \Delta} ; \quad \frac{\partial n_{1}^{i}}{\partial \gamma_{2}^{i}}=-\frac{\alpha_{1}-\gamma_{1}}{4 \Delta} \\
& \frac{\partial n_{2}^{i}}{\partial p_{1}^{i}}=-\frac{\alpha_{2}-\gamma_{2}}{2 \Delta} ; \quad \frac{\partial n_{2}^{i}}{\partial \gamma_{1}^{i}}=-\frac{\alpha_{2}-\gamma_{2}}{4 \Delta},
\end{aligned}
$$

where $\Delta=t_{1} t_{2}-\left(\alpha_{1}-\gamma_{1}\right)\left(\alpha_{2}-\gamma_{2}\right)$. Notice that in each case a small change in $\gamma$ has exactly half the effect of a small change in the corresponding $p$. The reason is that with equal market shares, the effect on the total charge an agent must pay with a change in $\gamma$ is half that with a change in $p$.

Platform $i$ 's profit is

$$
\pi^{i}=\left(\gamma_{1}^{i} n_{2}^{i}+p_{1}^{i}-f_{1}\right) n_{1}^{i}+\left(\gamma_{2}^{i} n_{1}^{i}+p_{2}^{i}-f_{2}\right) n_{2}^{i}
$$

Notice that expressions (A4)-(A7) imply that at any symmetric set of prices, we have

$$
\frac{\partial \pi^{i}}{\partial p_{1}^{i}}=2 \frac{\partial \pi^{i}}{\partial \gamma_{1}^{i}} ; \quad \frac{\partial \pi^{i}}{\partial p_{2}^{i}}=2 \frac{\partial \pi^{i}}{\partial \gamma_{2}^{i}}
$$

We will see that this feature of the market will generate a multiplicity of symmetric equilibria.

First, I show that platform $i$ 's objective function is concave given its rival's choice $\left(p_{1}^{j}, p_{2}^{j}, \gamma_{1}^{j}, \gamma_{2}^{j}\right)$, as long as $0 \leq \gamma_{1}^{j} \leq 2 \alpha_{1}$, and $0 \leq \gamma_{2}^{j} \leq 2 \alpha_{2}$ are nonnegative and the maintained assumption (8) holds. I need to show this so that I can characterize equilibria in terms of the first-order conditions. Usually, verifying that a function of four variables is concave is a tedious matter. However, in this context, I can easily reduce the number of $i$ 's strategic variables to two, which greatly simplifies the calculation. Given the rival prices $\left(p_{1}^{j}, p_{2}^{j}, \gamma_{1}^{j}, \gamma_{2}^{j}\right)$, it turns out that $i$ 's profits are a function 
only of the utilities $u_{1}^{i}$ and $u_{2}^{i}$ it offers its consumers. When it offers this pair of utilities, it will attract a certain number $n_{1}^{i}$ and $n_{2}^{i}$ of each group-I will shortly derive this relationship explicitly - and by combining expressions (A1) and (A8), its total profit can be written in terms of the utilities as

$$
\pi^{i}=\left(\alpha_{1} n_{2}^{i}-u_{1}^{i}-f_{1}\right) n_{1}^{i}+\left(\alpha_{2} n_{1}^{i}-u_{2}^{i}-f_{2}\right) n_{2}^{i}
$$

That is to say, any choice of $\left(p_{1}^{i}, \gamma_{1}^{i}\right)$ that leaves $u_{1}^{i}$ unchanged in (A1) generates the same profits for the platform. One implication of this is that a platform has a continuum of best responses to its rival's choice of tariffs. If I show that platform $i$ 's profits are concave in $\left(u_{1}^{i}, u_{2}^{i}\right)$, then I have done what is required.

To do this, I need to derive platform $i$ 's market shares as a function of its offered utilities and the rival's tariffs. Similarly to expressions (A2)-(A3), we have

$$
\begin{aligned}
& n_{1}^{i}=\frac{1}{2}+\frac{u_{1}^{i}-\left(\left(\alpha_{1}-\gamma_{1}^{j}\right)\left(1-n_{2}^{i}\right)-p_{1}^{j}\right)}{2 t_{1}} \\
& n_{2}^{i}=\frac{1}{2}+\frac{u_{2}^{i}-\left(\left(\alpha_{2}-\gamma_{2}^{j}\right)\left(1-n_{1}^{i}\right)-p_{2}^{j}\right)}{2 t_{2}} .
\end{aligned}
$$

Solving this pair of equations gives the following explicit expressions for market shares:

$$
\begin{aligned}
& n_{1}^{i}=\frac{1}{2}+\frac{\left(\alpha_{1}-\gamma_{1}^{j}\right)\left(u_{2}^{i}-\left(\frac{\alpha_{2}-\gamma_{2}^{j}}{2}-p_{2}^{j}\right)\right)+2 t_{2}\left(u_{1}^{i}-\left(\frac{\alpha_{1}-\gamma_{1}^{j}}{2}-p_{1}^{j}\right)\right)}{4 t_{1} t_{2}-\left(\alpha_{1}-\gamma_{1}^{j}\right)\left(\alpha_{2}-\gamma_{2}^{j}\right)} \\
& n_{2}^{i}=\frac{1}{2}+\frac{\left(\alpha_{2}-\gamma_{2}^{j}\right)\left(u_{1}^{i}-\left(\frac{\alpha_{1}-\gamma_{1}^{j}}{2}-p_{1}^{j}\right)\right)+2 t_{1}\left(u_{2}^{i}-\left(\frac{\alpha_{2}-\gamma_{2}^{j}}{2}-p_{2}^{j}\right)\right)}{4 t_{1} t_{2}-\left(\alpha_{1}-\gamma_{1}^{j}\right)\left(\alpha_{2}-\gamma_{2}^{j}\right)} .
\end{aligned}
$$

Notice that these market share functions are linear in utilities, and therefore profit in (A10) is quadratic in utilities. Profit is concave in utilities if (i) $\partial^{2} \pi^{i} / \partial\left(u_{1}^{i}\right)^{2}<0$ and (ii) the determinant of the matrix of second derivatives of $\pi$ is positive. Tedious calculations show (i) holds if

$$
4 t_{1} t_{2}>\left(\alpha_{1}+\alpha_{2}\right)\left(\alpha_{2}-\gamma_{2}^{j}\right)+\left(\alpha_{1}-\gamma_{1}^{j}\right)\left(\alpha_{2}-\gamma_{2}^{j}\right)
$$

which is true when the maintained assumption (8) holds and $0 \leq \gamma_{i}^{j} \leq 2 \alpha_{i}$. Also, (ii) holds if

$$
16 t_{1} t_{2}>\left(2 \alpha_{1}+2 \alpha_{2}-\gamma_{1}^{j}-\gamma_{2}^{j}\right)^{2}
$$

which holds under the same assumptions. I deduce that a platform's choice problem is concave.

Next, I characterize the symmetric equilibria. Suppose the two platforms choose the same pair of per-user charges $\left(\gamma_{1}, \gamma_{2}\right)$. From (A8) and using (A4) and (A7), the first-order condition $\partial \pi^{i} / \partial p_{1}^{i}=0$ evaluated at the symmetric fixed charges $p_{1}^{j}=p_{1}^{i}$ and $p_{2}^{j}=p_{2}^{i}$ yields

$$
p_{1}=f_{1}+t_{1}-\frac{\gamma_{1}+\gamma_{2}}{2}-\frac{\alpha_{2}-\gamma_{2}}{t_{2}}\left(\alpha_{1}+p_{2}-f_{2}+\frac{\gamma_{2}-\gamma_{1}}{2}\right),
$$

and similarly

$$
p_{2}=f_{2}+t_{2}-\frac{\gamma_{1}+\gamma_{2}}{2}-\frac{\alpha_{1}-\gamma_{1}}{t_{1}}\left(\alpha_{2}+p_{1}-f_{1}+\frac{\gamma_{1}-\gamma_{2}}{2}\right)
$$

Solving this pair of simultaneous equations in $p_{1}$ and $p_{2}$ implies that equilibrium fixed fees given the per-user charges $\left(\gamma_{1}, \gamma_{2}\right)$ satisfy expressions (17). Secondly, when the fixed fees on each platform are given by (17), one can show using (A8) and (A9) that a platform's optimal choice of per-user fees is $\left(\gamma_{1}, \gamma_{2}\right)$. Therefore, since the first-order approach is valid in this problem, the result is established. Q.E.D.

\section{References}

Anderson, S. And CoAte, S. "Market Provision of Broadcasting: A Welfare Analysis." Review of Economic Studies, Vol. 72 (2005), pp. 947-972.

Armstrong, M. “The Theory of Access Pricing and Interconnection.” In M. Cave, S. Majumdar, and I. Vogelsang, eds., Handbook of Telecommunications Economics: Vol. I. Amsterdam: North-Holland, 2002.

(C) RAND 2006 
- AND Vickers, J. “Competitive Price Discrimination.” RAND Journal of Economics, Vol. 32 (2001), pp. 579-605. AND Wright, J. "Two-Sided Markets, Competitive Bottlenecks and Exclusive Contracts.” Economic Theory, forthcoming.

BegGs, A. "Mergers and Malls.” Journal of Industrial Economics, Vol. 42 (1994), pp. 419-428.

Caillaud, B. and Jullien, B. "Chicken and Egg: Competition Among Intermediation Service Providers." RAND Journal of Economics, Vol. 34 (2003), pp. 309-328.

Dobson, P. And Waterson, M. "Countervailing Power and Consumer Prices.” Economic Journal, Vol. 107 (1997), pp. 418-430.

Dukes, A. And Gal-Or, E. "Negotiations and Exclusivity Contracts for Advertising." Marketing Science, Vol. 22 (2003), pp. 222-245.

Gabszewicz, J., Laussel, D., And Sonnac, N. "Press Advertising and the Ascent of the 'Pensé Unique." European Economic Review, Vol. 45 (2001), pp. 641-651.

KaISER, U. AND Wright, J. "Price Structure in Two-Sided Markets: Evidence from the Magazine Industry." International Journal of Industrial Organization, Vol. 24 (2006), pp. 1-28.

Klemperer, P. AND Meyer, M. “Supply Function Equilibria in Oligopoly Under Uncertainty.” Econometrica, Vol. 57 (1989), pp. 1243-1277.

Rochet, J.-C. And Tirole, J. "Platform Competition in Two-Sided Markets." Journal of the European Economic Association, Vol. 1 (2003), pp. 990-1029.

— AND — .Two-Sided Markets: A Progress Report.” RAND Journal of Economics, Vol. 37 (2006), pp. 645-667.

Rysman, M. "Competition Between Networks: A Study of the Market for Yellow Pages." Review of Economic Studies, Vol. 71 (2004), pp. 483-512.

Schulz, N. And STAHL, K. "Do Consumers Search for the Highest Price? Oligopoly Equilibrium and Monopoly Optimum in Differentiated-Products Markets.” RAND Journal of Economics, Vol. 27 (1996), pp. 542-562.

Smith, H. AND Hay, D. "Streets, Malls and Supermarkets." Journal of Economics and Management Strategy, Vol. 14 (2005), pp. 29-59.

Stahl, K. "Location and Spatial Pricing Theory with Nonconvex Transportation Cost Schedules." Bell Journal of Economics, Vol. 13 (1982), pp. 575-582.

van RaAlte, C. AND Webers, H. "Spatial Competition with Intermediated Matching." Journal of Economic Behavior and Organization, Vol. 34 (1998), pp. 477-488.

Wright, J. “Access Pricing Under Competition: An Application to Cellular Networks.” Journal of Industrial Economics, Vol. 50 (2002), pp. 289-316. 